\title{
Reflections on a community-based service learning approach in a geoinformatics project module
}

\author{
Serena Coetzee and Victoria Rautenbach \\ Centre for Geoinformation Science, Department of Geography, Geoinformatics and \\ Meteorology, University of Pretoria, Pretoria, South Africa
}

\begin{abstract}
Geoinformatics (also known as geographic information science) is the science and technology that underpins the collection, representation, processing, analysis, visualisation and dissemination of geographic information. Such information is hugely valuable in solving environmental and social problems in society. In this paper we reflect on a communitybased service learning approach in a third year geoinformatics module. Students mapped an informal settlement, captured information about dwellings and conducted a number of studies in support of environmental and social problem solving. The aim was to raise awareness of social issues, to understand students' sense of social responsibility and their understanding of the role of geoinformatics in solving community problems. After completion of the module, we conducted in-depth interviews with ten students. The results confirm the value of community-based service learning in enhancing understanding of theoretical concepts and contributing to local communities. Further work is needed to better understand how South African geoinformatics students can be made aware of the role of geoinformatics in solving problems in society.
\end{abstract}

Keywords: social responsibility, community-based service learning, geoinformatics, geographic information science, informatics, education

\section{Introduction}

Humanity is currently facing many global challenges, such as climate change, global health problems, extreme poverty and rising wealth inequality [1]. Many of these challenges can be linked to egoism, i.e. acting in the interest of one's self without consideration for others. For example, by not considering the carbon footprint when buying imported fruits. Geoinformatics professionals, through the use of geographic information, have enormous potential to contribute towards addressing these challenges. However, one needs to have a sense of social responsibility to want to contribute to solving such challenges that are not of direct interest to oneself.

Social responsibility is the obligation that an individual or organisation feels to society and specifically the disadvantaged $[2,3,4]$. Social responsibility combines 
the values and actions rooted in the obligation to contribute to society [5], i.e. one should act in accordance with care, objectivity, and considering others' perspectives and the impact of one's actions [6]. Canney and Bielefeldt [3] argue that engineers need a well-developed sense of social responsibility in order to contribute to social and development problems of underserved populations. The same can be said about many other professions, including geoinformatics professionals.

Social responsibility education is of interest in many disciplines, but we could not find any that focus on geoinformatics. Canney and Bielefeldt [6] suggested that an understanding of professional social responsibility would nurture the required skills and attitude in engineering students, and encourage them to use their skills to address global challenges. They developed an integrated model to help understand the development of personal and professional social responsibility in engineers. The model has been used to evaluate engineering students' views on social responsibility $[4,6,7,8]$. According to Leveson and Joiner [9], historically, business education has focused on the procedural, organization-centric, geared towards the ethics of personal advantage. In contrast, teaching social responsibility requires appreciation for the views and values of students [9]. Harvey [10] proposes that the education of GIScience and technology professionals should go beyond abstract scholarly ethics to applied approaches based on practical wisdom.

Service learning is an experiential pedagogy in which community service is integrated into academic activities [11]. The aim is to enhance understanding of theoretical concepts and to facilitate contributions to local communities [12]. Dorsey [13] highlights that community-based learning provides unique opportunities for students to implement theoretical knowledge and gain hands-on experience while trying to address a real-world issue. The focus of service learning is on the student: the student learns from and contributes to the community, while the community benefits and contributes to the student's learning [11]. Warren [12] reports that many studies have shown service learning to have positive effects on students' cultural awareness and social responsibility, and that it encourages students to act as responsible citizens. In the United States, the integration of service learning into academic curricula is increasing [11] and in some South African engineering and information technology faculties, a community-based project is compulsory [14]. Community-based service learning has been applied in various fields, including architecture, education, engineering, health science and geography $[13,15,16,17,18,19]$, but to our knowledge, studies in geoinformatics, which combines geography with technology, have not been done.

In this paper we conducted qualitative research that reflects on a communitybased service learning approach in a third year geoinformatics module. This was the students' first opportunity to apply geoinformatics knowledge and skills acquired through their undergraduate studies in a single project from conception to completion. Students mapped an informal settlement, captured information about dwellings and conducted a number of studies in support of environmental and social problem solving. The aim was to raise awareness of social issues. We also 
wanted to understand students' sense of social responsibility and their perception of the role of geoinformatics in solving community problems. After completion of the module, we conducted in-depth interviews with ten students. The remainder of the paper is structured as follows. Section 2 provides background about the community project. Section 3 explains how the interviews were conducted. In section 4 , the results of the interviews are presented and discussed, followed by a conclusion in section 5 .

\section{Community-based service learning - Mapping the informal settlement of Alaska, Mamelodi}

The University of Pretoria has a long-standing partnership with the Viva Foundation, in the Alaska informal settlement in the City of Tshwane, to improve the safety of the informal settlement dwellers. The Viva Foundation aims to transform informal settlements and other high-priority poverty areas into stable and economically viable communities (www.viva-sa.co.za). Amongst others, the Viva Foundation coordinates the South African People's Response Initiative (SAPRI) project, which provides the settlement dwellers with panic buttons that can be used to call for assistance in case of emergencies. In 2015, the final year geoinformatics students worked on improving the SAPRI project that is currently paper based, by mapping the most southern part of Alaska immediately surrounding the Viva centre. Viva community care workers accompanied the students to introduce them to the community members and to provide them with additional information about the community and its history.

Over the course of three days, seventeen final year students captured the locations of 1350 dwellings in Alaska, as well as information about each dwelling, such as the address and the use of the dwelling (e.g. home, tuck shop or shebeen). This digital information was handed to the SAPRI project. In addition, the students investigated the following: 1) optimal distribution of the panic buttons; 2) identifying areas that are potentially at risk of damage during thunderstorms (based on terrain and slopes); 3) planning emergency response routes to dwellings during fires; and 4) identifying a suitable location for a health post in Alaska. Each of these investigations addresses a specific need in the community. A number of maps (hardcopy and interactive) of these investigations were given to the Viva Foundation.

This community project was integrated into the academic activities of the semester module, GMT 320 (Geoinformatics project). The module provides a unique first learning opportunity for the students to be involved in a real-life project with a client. Up until then, students work with hypothetical scenarios where "perfect" data and a breakdown of the solution are provided to them. For GMT 320, students have to implement the entire project management process, capture their own data, and then implement an innovative solution with the data they have captured. During GMT 320 students get a first opportunity to work with 
handheld and differential global positioning system (GPS) devices, and to gain fieldwork experience. This experience is invaluable to the students who will plan projects and capture data in the field during their professional careers.

\section{Methodology}

The final year geoinformatics students completed the community project in the second semester of 2015. In March 2016, these students were invited to participate in an in-depth interview on their experience and thoughts on social responsibility. Due to the small number of participants and the type of interview, this research is of a qualitative nature.

Before the interview was conducted, the participants were asked to complete an adapted version of the Engineering Professional Responsibility Assessment $(\text { EPRA })^{1}$ survey. The only adaptation was replacing engineering with 'GISc' in the text. We used the assessment from the engineering discipline because a questionnaire for geoinformatics does not exist. Similar to engineers, geoinformatics professionals are sometimes involved in solutions designed to solve problems of underserved populations. A social responsibility score (SR score) between 8 and 56 was calculated based on the description by Canney [5], and Rulifson and Bielefeldt [8] who designed the EPRA survey. The SR score provides an indication of a participant's degree of social responsibility; a higher SR score indicates a participant who is more aware of social responsibility.

The interviews were conducted in March 2016. They consisted of eighteen questions and were 30 to 60 minutes long. The questions covered a variety of topics, such as undergraduate experience, general opinion on social issues and how the community-based service learning module influenced their views. The interview questions are presented in Table 1. The questions are adapted from Rulifson and Bielefeldt $[7,8]$. The sessions were voice recorded and the interviewers also took notes during the session.

\section{Results and discussion}

\subsection{Overview of participants, SR scores and EPRA survey results}

Ten geoinformatics students accepted the invitation to participate in the interviews. All of them completed the GMT 320 module with the community-based service learning approach in 2015. Table 2 provides an overview of the participants. The group consisted of six male and four female participants from various ethnicities (African, Indian and European). The ages ranged from 21 to 29 years.

\footnotetext{
${ }^{1}$ Available online at http://bit.ly/2al9F0u
} 
Table 1. Interview questions

1. Why did you decide to study BSc Geoinformatics?

a. Where did you hear about geoinformatics for the first time?

2. Was BSc Geoinformatics your first qualification?

b. If not, why did you decide to do another degree?

3. Did you change from another degree to BSc Geoinformatics?

c. If yes, for which degree were you registered before switching to BSc Geoinformatics?

d. Why did you change to BSc Geoinformatics?

4. Experience during your undergraduate geoinformatics degree:

a. Positive experiences? What did you enjoy?

b. Negative or frustrating experiences?

5. What interests you the most about geoinformatics?

a. Why do you like geoinformatics?

b. What motivated you through the tough classes?

6. What is your ideal future career path currently? Why?

7. Are you looking for any specific qualities of a job and company? Why are these qualities important?

8. Do you already know of companies where you'd like to work (not considering bursaries obligations)? If so, which ones?

9. Do you do any volunteer or community work?

a. If yes, at which scale: globally, locally, within your family/friends?

b. How and why are you involved? What are the benefits you see for them and yourself?

10. What social issues are important to you?

a. Did anything influence you to see these issues as important?

b. How do you see yourself involved in these social issues?

c. Do you see geoinformatics playing a role in addressing these issues?

11. How would you define social responsibility?

Provide definition of social responsibility:

Based on Rulifson and Bielefeldt [7] and Herkert [19], social responsibility and a GISc professional's social responsibility:

Social responsibility is the ethical duty one has to act in ways that benefit society

A GISc professional's social responsibility encompasses protecting public welfare, and extends to

concerns around environmental protection and sustainability, the social context of GISc work, empathy and caring, striving for social justice and peace, and pro bono work.

12. Did GMT320 influence the social issues you consider important?

13. Did GMT320 affect your understanding of social responsibility?

14. After completing GMT320, do you expect social responsibility to be part of your future geoinformatics career?

a. How?

b. How strongly?

c. In what ways?

15. After completing GMT320, does your sense of social responsibility move you towards or away from a geoinformatics career?

a. Are there certain kinds of geoinformatics work that you will avoid?

b. Are there certain kinds of geoinformatics work that you will prefer or go for?

16. Is there one social issue that you feel particularly passionate about trying to address?

a. Why?

b. Can your geoinformatics abilities help with this issue?

c. Can other majors in geoinformatics better help you to address this issue?

17. Thinking about your experience during the GMT320 field work and community engagement:

a. Positive experiences? What did you enjoy?

b. Negative or frustrating experiences?

c. What did you like about the fieldwork? What not?

d. What motivated you through the tough times?

18. Is there anything else you would like to share, or questions you have? 
Six participants indicated that they are religious (i.e. affiliated with an organized religion), and two participants specified that they are spiritual. Six participants indicated that they have been in an informal settlement prior to the community project, and nine have been in a township. Only three participants had previous work experience in the form of a part-time job or internship. An SR score was calculated for each participant. Two male participants had the highest SR score (above 50), followed by most of the remaining participants with a SR score between 42 and 45 . The lowest score was 38,92 .

Table 2. Overview of the participants

\begin{tabular}{|c|c|c|c|c|c|c|c|c|c|c|}
\hline Participant & P1 & P2 & P3 & P4 & P5 & P6 & P7 & P8 & P9 & P10 \\
\hline SR score & 45.35 & 50.67 & 38.92 & 42.43 & 43.55 & 43.16 & 43.75 & 53.77 & 42.35 & 42.24 \\
\hline Age & $\underset{\pi}{\pi}$ & $\underset{\mathbb{V}}{\mathbb{V}}$ & $\underset{\lambda}{\Lambda}$ & $\underset{\mathbb{N}}{\mathbb{V}}$ & $\underset{\mathbb{N}}{\mathbb{V}}$ & $\tilde{\lambda}$ & $\underset{\mathbb{N}}{\mathbb{V}}$ & $\underset{\mathbb{N}}{\mathbb{N}}$ & $\widetilde{\Lambda}$ & $\underset{\mathbb{V}}{\mathbb{V}}$ \\
\hline $\begin{array}{l}\text { Have you been in } \\
\text { an informal } \\
\text { settlement prior to } \\
\text { GMT320 in } 2015 ?\end{array}$ & No & Yes & Yes & No & Yes & Yes & Yes & No & No & Yes \\
\hline $\begin{array}{l}\text { Have you been in a } \\
\text { township prior to } \\
\text { GMT320 in } 2015 \text { ? }\end{array}$ & No & Yes & Yes & Yes & Yes & Yes & Yes & Yes & Yes & Yes \\
\hline $\begin{array}{l}\text { Previous GISc } \\
\text { work experience }\end{array}$ & ż & ż & : & : & : & 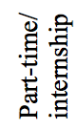 & : & 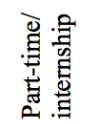 & 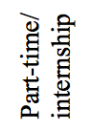 & 亏ั \\
\hline
\end{tabular}

In the EPRA survey, participants were asked to indicate which job qualities are important to them in a future job. Fig. 1 shows how participants rated these job qualities. Community development is rated as important by all participants, but only three participants rated it above 10\% (at 20\%). Helping people is rated above $10 \%$ by all participants, except two who rated it $10 \%$ and one did not consider it as important at all. Most participants (except one) rate salary as an important job quality ( $20 \%$ or above). This can probably be explained by the fact that most participants are in their fourth year of study and will have accumulated some study debt.

The EPRA survey also covered the reasons for volunteering currently or in the past (see Fig, 2). $60 \%$ of the participants indicated that the main motivation for volunteering is/was to gain a new skill or that it was required for class. $40 \%$ indicated that helping others is/was the motivation. Religious participants typically participated in volunteering activities organised by their religious communities. No participant indicated that international travel was a motivation for volunteering. 


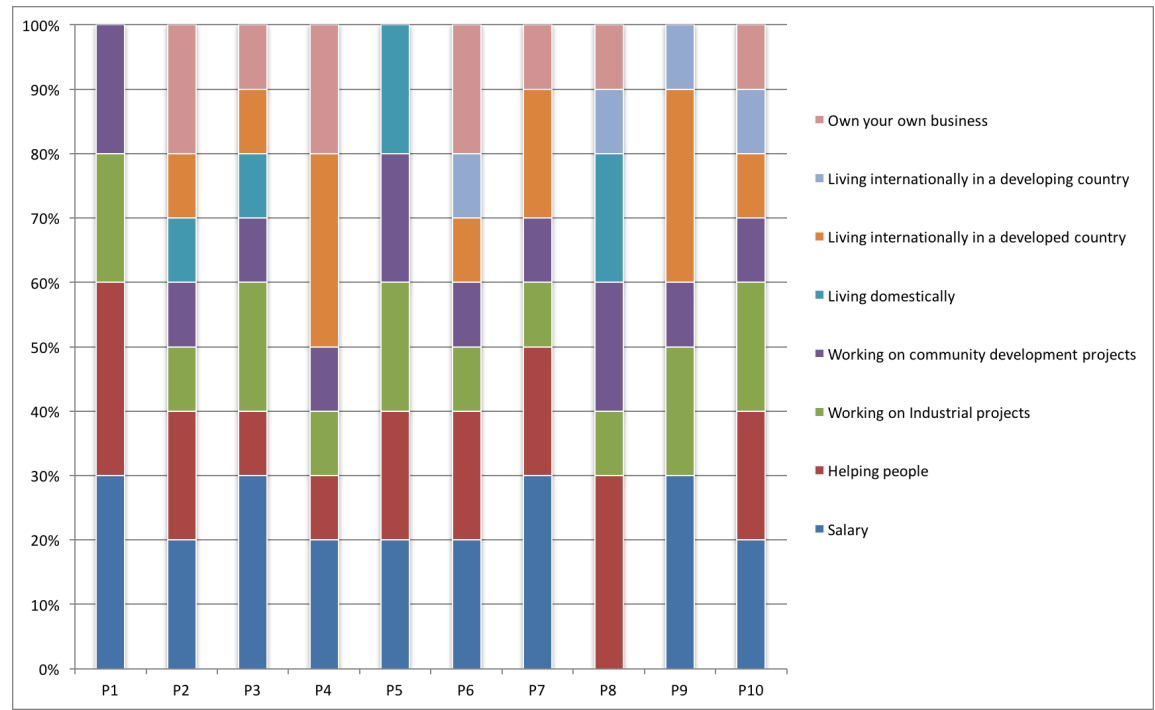

Fig. 1. Important job qualities as indicated per participant

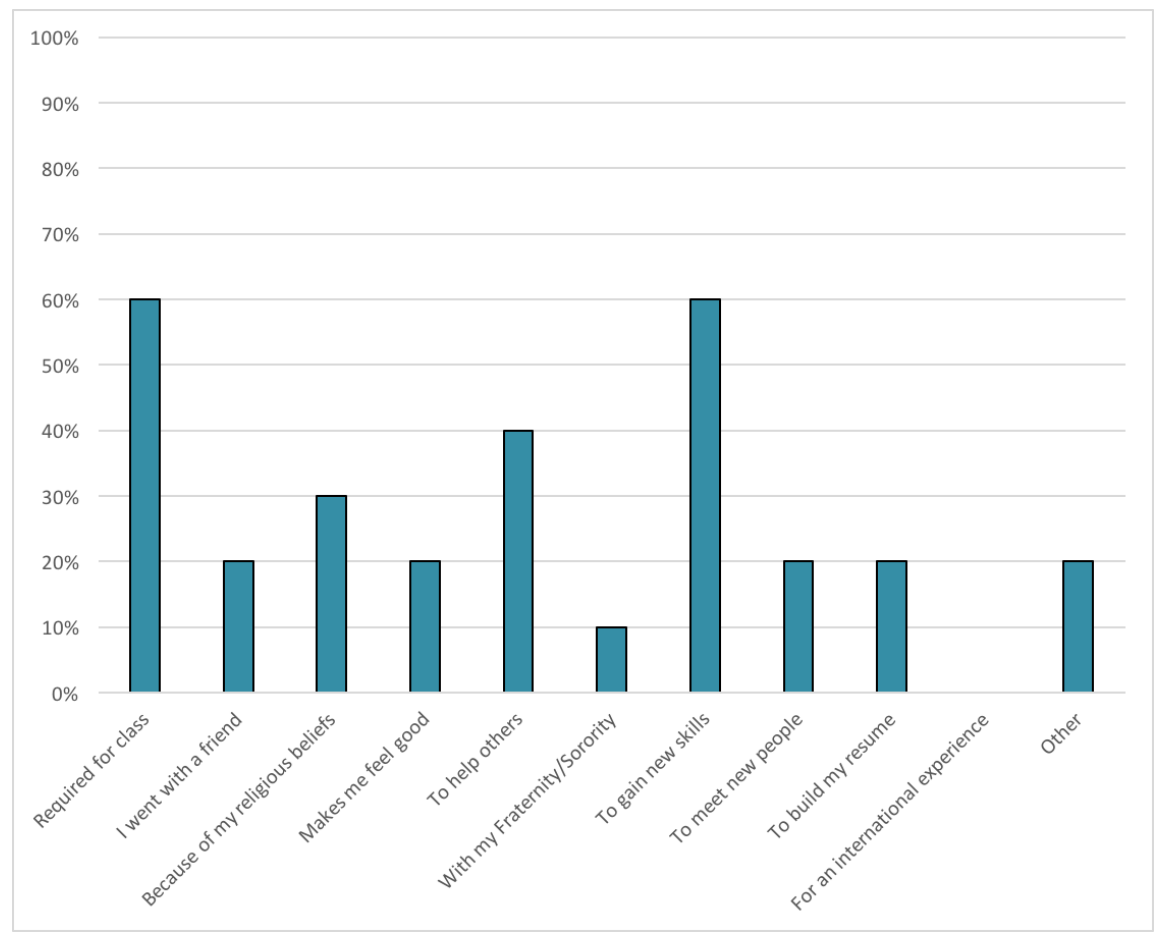

Fig. 2. Reasons provided by participants for volunteering currently or in the past 
Fig. 3 shows the breakdown of factors that currently or previously inhibited participation in volunteer activities. The largest factor is lack of time due to course work (28\%). $16 \%$ of participants indicated that they did not know how to get involved in volunteering. Financial limitations (13\%) and lack of time due to work obligations $(13 \%)$ were also significant factors.

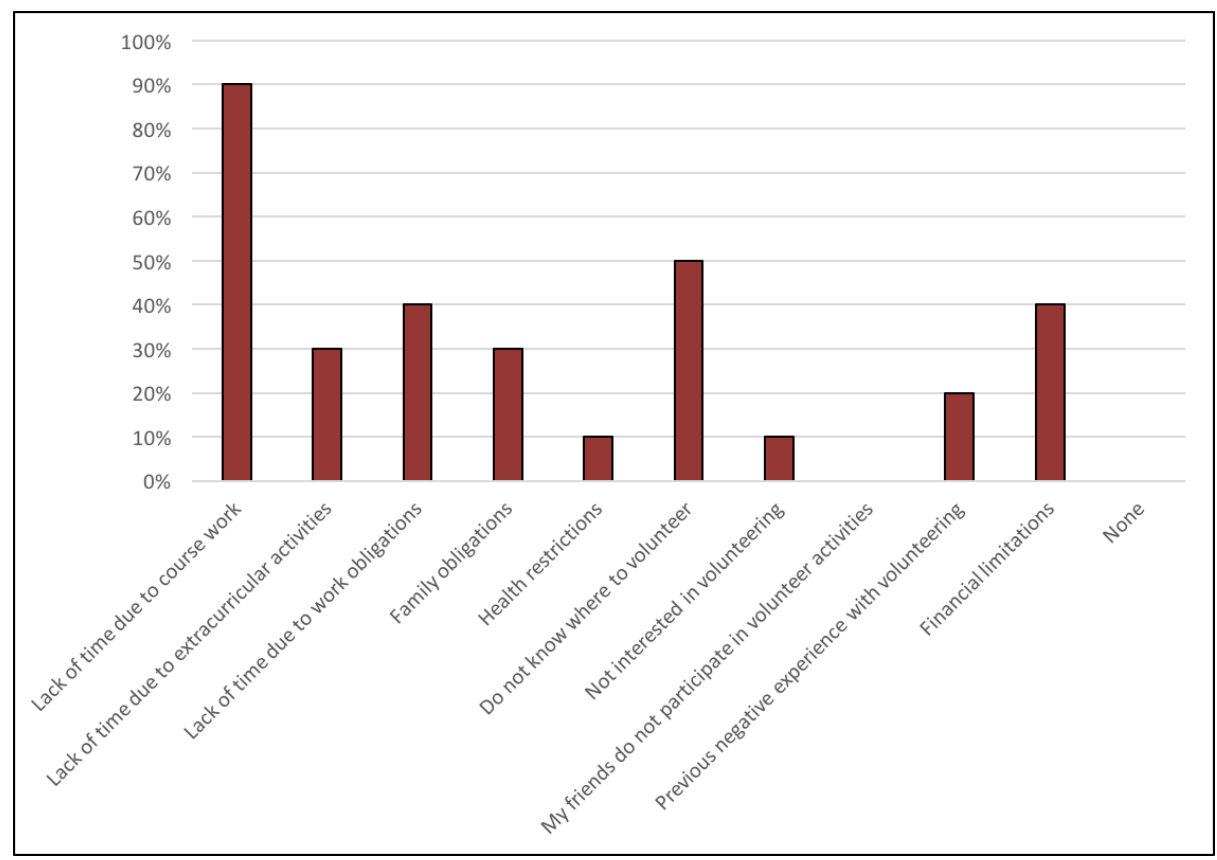

Fig. 3. Factors that currently or previously inhibited participation in volunteer activities

\subsection{Results and discussion of interviews}

In this section, we present and discuss the interview results under the following topics: perception of social responsibility; social issues considered important; role of geoinformatics; future career in geoinformatics in solving community problems; reasons for studying geoinformatics; and experience during community-based service learning module. These topics serve to reflect on the objective to raise awareness of social issues, and to contribute to understanding students' sense of social responsibility and their perception of the role of geoinformatics in solving community problems.

Perception of social responsibility. Each participant completed the EPRA survey before starting his/her interview. The survey includes definitions for community service, social responsibility, social justice and pro bono. Social responsibility is defined as "an obligation that an individual (or company) has to act with concern 
and sensitivity, aware of the impacts of their actions on others, particularly the disadvantaged" [5]. Participants would have read this definition in the survey, but were asked again halfway through the interview to define social responsibility. The participants' definition of social responsibility helps to understand their attitude towards social responsibility and how they exploit volunteerism.

All participants were able to identify aspects of social responsibility in their definition. The focus was on community or society, followed by a focus on benefits. This focus encapsulates two key points of social responsibility. However, the concept of ethical duty was only mentioned, as 'obligation', by one participant. The following four distinct definitions illustrate participants' diverse perceptions of social responsibility:

- One participant defined social responsibility as "your obligation to act in such a way that you positively affect the greater community".

- One participant spoke about assisting a community to the extent of one's abilities. This idea of 'to the extent of one's abilities' aligns with the 'proportional to the opportunities and skills which one has been afforded' in the definition by Rulifson and Bielefeldt [8].

- One participant had a very different view on social responsibility and focused more on not being involved in unethical practices and using one's skills to benefit society. Social responsibility is strongly connected to ethics and ethical duty, and it was interesting that this participant focused on unethical practices.

- One participant had a more passive approach to social responsibility and stated that one should "not make things worse".

Participants with a high SR scores provided more accurate definitions of social responsibility and reported previous involvement in volunteerism. For example, one participant provided a near accurate definition of social responsibility. This participant has a strong sense of social responsibility (highest SR score); indicated a religious preference; indicated five reasons for volunteering (highest number of reasons), and also detailed involvement in weekly volunteer activities relating to church, tutoring and everyday activities. On the other end of the spectrum, a participant with a low SR score reported lack of time and interest in volunteering as major factors inhibiting volunteering. This participant indicated a focus on environmental issues in the interview, while the EPRA survey was focused on volunteering related to humans. These results suggest that the EPRA survey can determine whether a participant has a sense of social responsibility towards humans. However, it is not suitable to identify social responsibility towards the environment.

Social issues considered important. During the interview, the participants were asked twice which social issues are important to them; before (question 10) and after (question 16) discussion of the community-based service learning module (GMT 320). From the discussion, it was evident that participants' background 
greatly influenced the social issues that they consider important. Below three specific motivations for social issues are discussed:

- One participant considers gender equality as important, and mentioned that ethnicity and family background were the main influences for considering these issues as important. In many communities in South Africa and across the world, women are still fighting against gender discrimination.

- Three participants are in the ethnic group that was previously disadvantaged in South Africa. All three participants consider education as the one social issue that they are passionate about. The three participants are from various (urban and rural) areas in South Africa and from different age groups, but all of them believe that education is important for people to improve themselves and their living circumstances.

- Three participants indicated that environmental issues are important to them. One of them was a Junior Honorary Ranger (http://www.sanparksvolunteers.org/) while at school. The participant volunteered in the South African National Parks (SANParks), amongst others, by removing alien invasive plants and identifying snares. Similarly, another participant had a botanist family member and grew up helping with Environmental Day interventions (e.g. litter clean-up or alien invasive plant projects in local nature reserves).

Fig. 4 provides an indication of how the participants changed their consideration of important social issues after discussing their experience of the community project. The graph shows the number of participants who indicated a specific issue in their responses to questions 10 and 12. After the discussion, participants were asked to single out one social issue that they are most passionate about. It is interesting to note that lack of service delivery was mentioned as a social issue for the first time after the discussion. This can be attributed to the lack of service delivery infrastructure in Alaska, Mamelodi. Other issues that received more attention afterwards are education, poverty and environmental issues. This shows that the experience in the community-based service learning module has raised their awareness of important social issues in the community.

Role of geoinformatics in solving community problems. The participants were asked how geoinformatics could be used to address social issues. This question focuses on the practical application of geoinformatics. All participants stated that geoinformatics could assist with mapping the issues, thus making them more visible. However, geoinformatics is generally also used to understand a social issue, aid in decision making, and sometimes also in identifying possible solutions. Only four participants focused on using geoinformatics to solve a social issue, and three on visualizing an issue to understand it better. Two participants stated they could be role models as geoinformatics professionals and that this could inspire others to overcome social issues, such as gender equality and poverty through education. One participant focused on using their education to educate others in less fortunate communities. These results suggest that the role of geoinformatics 
in understanding social problems and in solving them needs to receive more attention in the undergraduate curricula.

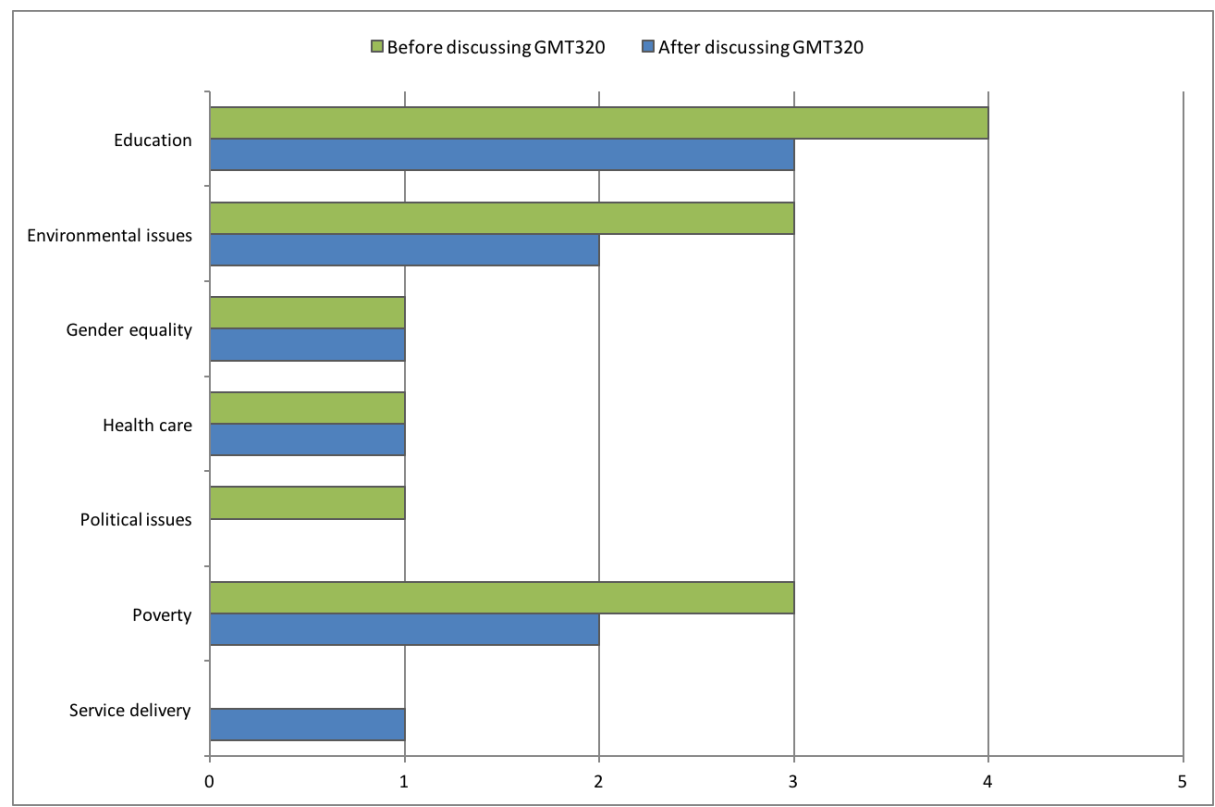

Fig. 4. Social issues mentioned by participants during the interview

Future career in geoinformatics. Fig. 1 provides an overview of the job qualities that participants indicated as important to them in the EPRA survey. To supplement this question, the participants were asked in the interview: 1) to describe their ideal future career; 2) which sector they would prefer to work for; 3) possible companies that they have identified for future employment; and 4) the qualities of a job or company that they consider important.

The participants are all in their $4^{\text {th }}$ year of study, and most of them are likely to enter the job market at the end of this year. Five participants indicated that they would prefer an opportunity to work as a geoinformatics analyst, and one participant as a geoinformatics project manager. Geoinformatics analyst is the most common career path for a geoinformatics graduate, and the result is thus as expected. Four participants would prefer to start their own businesses; three of them in geoinformatics. Lastly, one participant indicated a research position in interdisciplinary research in mining and agriculture.

When asked if they would prefer a job opportunity in the public sector, private sector or at a non-governmental organization, the majority of participants (eight) indicated that they would favour a position in the private sector. The variety of projects, perceived challenges they would face, and making a greater impact was cited as motivators for the private sector. The remaining two participants indicated that they would prefer the public sector, because it offers a comfort zone and because of the additional employee benefits in the public sector. Currently, 
most participants (seven) do not have a preference for a future employer. Google and Esri were identified as ideal future employers in the private sector, and local municipalities or parastatals, such as Eskom, in the public sector.

The wordle in Fig. 5 provides an overview of the keywords that the participants used when describing the qualities that are important to them in a job opportunity or company. From the figure it is clear that a good work environment is most important to the participants, followed closely by opportunity for progress, variety of projects and a good salary. Two participants mentioned that community work would be important qualities for them.

The participants were asked which opportunity they would pursue if offered two positions of equal pay, one opportunity with a focus on social responsibility projects (i.e. community projects) and the other one not. All participants, except one, selected the job opportunity with social responsibility projects. The participant who did not select the social responsibility opportunity, motivated this choice by stating that such an opportunity would be emotionally draining and that it would be difficult to separate work from personal life. The participant would prefer to be involved in community projects or volunteering in a personal or private capacity.

$$
\begin{gathered}
\text { mission honesty } \\
\text { growth opportunity technical support vision } \\
\text { innovation jothics job } \\
\text { empowerment } \\
\text { prospectstransparency } \\
\text { creditcommunity }
\end{gathered}
$$

Fig. 5. Key qualities mentioned by the participants (produced with www.wordle.net)

Reasons for studying geoinformatics. To get a better understanding of the participants reasons for studying geoinformatics, they were asked: 1) why did they study geoinformatics?; 2) what in geoinformatics interests them?; 3) what do they like about geoinformatics?; and lastly, 4) positive and negative experiences during their undergraduate geoinformatics studies.

Seven participants were motivated by their geography school teacher to study geoinformatics. This started commonly as a love for geography and maps, and the job opportunities available in geoinformatics. Many participants also mentioned a love of technology. Two participants have previous qualifications, in archi- 
tecture and surveying respectively. They indicated that they started studying geoinformatics because the previous degree was not a good fit for them or did not allow personal growth. After graduation, one participant is now perusing a degree in civil engineering, as he discovered a love for engineering through his undergraduate studies.

The range of possibilities and versatility of the application of geoinformatics interests participants about the field. They also mentioned that geoinformatics is new and still evolving and could thus provide them with numerous challenges. The use of software and tools to perform analyses, and the more practical use of geoinformatics were the aspects that the participants liked the most about geoinformatics.

The community-based service learning module was mentioned by five participants as a positive experience during their undergraduate studies. Their experience during this module will be presented in the next sub-section. Other positive experiences include learning new skills and the wide range of modules in different subjects in their first year of study (these include human geography, geomorphology, environmental sciences, meteorology, programming, systems theory, and information systems theory). However, some participants considered the large number of subjects and their relevance as frustrating. Programming modules were regarded as both positive and negative experiences, depending on whether participants found them challenging or not. Participants agreed that once they grasped the concept of programming, it turned into a positive experience. Nevertheless, most participants would not pursue a career in geoinformatics software development, and prefer analysis work. Interacting with industry representatives and guest lectures were positive experiences for five participants. Financial problems were negative experiences for some participants, and also motivated them through tough times (to avoid payment for repeating modules). One participant was motivated to make their family proud.

Experience during the community-based service learning module. GMT 320 is the first module during their undergraduate degree for which only geoinformatics students can enrol. Positive experiences during the module included the opportunity to do field work; getting hands-on experience using a GPS; completing a project from start to finish; and engaging with the community. All participants mentioned community interaction as a positive experience. They enjoyed learning about the community and sharing their knowledge about aerial photographs and GPSs with the community. The community was an inspiration to the participants because its members have so little, but are nevertheless full of pride.

The terrain, heat and the language barrier were challenges during the fieldwork, but provide the students with a true reflection of fieldwork in the 'real world'. The participants cited the need for the data to complete their project as their main motivation when fieldwork got tough. A frustrating, but positive experience, that most participants mentioned was the challenge of integrating the data captured by the four groups. As a result of poor planning, the integration was not optimal 
and had to be repeated more than once. This was definitely an obstacle for the participants, but all participants noted that this mistake had taught them the importance of proper planning when starting a project.

The participants were very grateful for the opportunity to work with the Viva Foundation, but due to their many other priorities and commitments, the participants experienced Viva as having a lack of interest in the community project. This led them to question the usefulness of the project. One participant also had a bad previous experience with a community project (everything that the students contributed with their community project was destroyed after a few months) and that had influenced the participant's perspective on community engagement. Such experiences may negatively influence the participants' willingness for future community engagement.

\section{Conclusion}

In this paper we presented students' experiences of a community-based service learning approach in a third year geoinformatics module. Students mapped an informal settlement, captured information about dwellings and conducted a number of studies in support of environmental and social problem solving. The aim was to raise awareness of social issues. We also wanted to understand students' sense of social responsibility and their perception of the role of geoinformatics in problem solving. After completion of the module, we conducted qualitative research through in-depth interviews with ten students.

After completion of the module in the second semester of 2015, in-depth interviews were conducted with ten students in March 2016. Before each interview, the participant completed a professional responsibility assessment (EPRA) from which a social responsibility score was calculated. The EPRA survey was developed to better understand students' attitude towards social responsibility and the effectiveness of educational interventions. An SR score for each participant was calculated from the EPRA survey, and showed that all participants, except one, scored in the upper quarter, meaning that most of them have a high sense of social responsibility.

Results of the in-depth interviews show that the participants have diverse perceptions of social responsibility; some can even be regarded as misperceptions. A strong social responsibility score correlates with a participant's involvement in volunteering. The participants' experience in the community-based service learning module has raised their awareness of important social issues in the community, such as education, poverty, environmental issues and the lack of service delivery infrastructure. If given the choice, participants would prefer to work for an organisation that is involved in social responsibility projects.

Participants mentioned visualization and mapping as a means of raising awareness of social challenges through geoinformatics. The participants' responses to 
questions about the role of geoinformatics in addressing challenges, suggest that the role of geoinformatics in understanding social problems and in solving them needs to receive more attention in the undergraduate curricula. The real world experience of the community project provided the participants with valuable lessons for their future careers. It taught them about the numerous challenges one may face in fieldwork, such as terrain, weather and data integration. Additionally, students learned the importance of planning. They needed to plan how four groups would go about capturing data and how the data would be integrate into a single harmonised dataset.

The results of the in-depth interviews confirm the value of community-based service learning in enhancing understanding of theoretical concepts $[12,13]$ and facilitating contributions to local communities [12]. In addition, the experience prepared students for their future career, as also reported by Helzer [18].

Generally, interview participants reported a love of geography, maps and technology as the reason for choosing geoinformatics as a career. The range of possibilities and versatility of the application of geoinformatics interests participants about the field, there was no mention of contributing to society as a reason for becoming a geoinformatics professional. These results are significantly different to EPRA survey results with engineering students in the US who generally linked engineering to social responsibility in some manner [7]. However, more studies need to be done to make any general conclusion.

This was a first experience with a community-based service learning approach in a geoinformatics module and it raises many questions for further work. For example, in future, we will ask students about their perceptions of social responsibility before and after completion of the module. This will provide a clearer indication of how the module influenced their perceptions. The professional responsibility assessment needs to be revised to consider both human and environmental issues, as both are relevant to geoinformatics work. The assessment questions also need to be adapted to be more suitable for geoinformatics students (as opposed to engineering) and they should consider South African circumstances. For example, international travel as a motivation for volunteering seems to be irrelevant to South African students.

South Africa has a highly diverse population with a Gini coefficient of $59.3^{2}$, indicating very high wealth inequalities in the population. There are also many environmental and social challenges to be addressed and it is important to understand how geoinformatics students can be made aware of the role of geoinformatics in addressing these challenges.

\footnotetext{
${ }^{2}$ http://data. worldbank.org/indicator/SI.POV.GINI?locations=ZA
} 


\section{Acknowledgements}

We would like to thank the Viva Foundation for the productive collaboration on the GMT 320 project in Alaska. We appreciate the financial support for transportation of the students to the informal settlement provided by Community Engagement at the University of Pretoria. Finally, we would like to acknowledge the contribution by the ten students who participated in the interviews.

\section{References}

1. United Nations: United Nations Sustainable Development Goals. Available online at http://www.un.org/sustainabledevelopment/sustainable-development-goals/ [accessed 25 July 2016], (2015).

2. Hamilton, C., Flanagan, C.: Reframing Social Responsibility Within a TechnologyBased Youth Activist Program. American Behavioral Scientist, 51(3), 444-465 (2007).

3. Canney, N.E., Bielefeldt, A.: A Model for the Development of Personal and Professional Social Responsibility for Engineers. In: 199th ASEE Annual Conference and Exposition, San Antonio, USA (2012).

4. Bielefeldt, A., Canney, N.: Social Responsibility Attitudes of First Year Engineering Students and the Impact of Courses. In: 121st ASEE Annual Conference and Exposition, Indianapolis, USA (2014).

5. Canney, N.E.: Assessing Engineering Students' Understanding of Personal and Professional Social Responsibility, PhD thesis, University of Colorado (2013).

6. Canney, N., Bielefeldt, A.: A framework for the development of social responsibility in engineers. International Journal of Engineering Education. 31, 414-424 (2015).

7. Rulifson, G., Bielefeldt, A.: Understanding of Social Responsibility by First Year Engineering Students: Ethical Foundations and Courses. In: 121st ASEE Annual Conference and Exposition, Indianapolis, USA (2014).

8. Rulifson, G., Bielefeldt, A.: Engineering Students' Varied and Changing Views of Social Responsibility. In: 122nd ASEE Annual Conference and Exposition, Seattle, USA (2015).

9. Leveson, L., Joiner, T.A.: Exploring corporate social responsibility values of millennial job-seeking students. Education + Training. 56, 21-34 (2014).

10. Harvey, F.: Values, choices, responsibilities: thinking beyond the scholarly place of ethics for the GIScience and technology profession and GIScience. Journal of Geography in Higher Education. 38, 500-510 (2014).

11. Pedersen, P.J., Meyer, J.M., Hargrave, M.: Learn Global; Serve Local: Student Outcomes From a Community-Based Learning Pedagogy. Journal of Experiential Education. 38(2), 189-206 (2015).

12. Warren, J.L.: Does Service-Learning Increase Student Learning?: A Meta-Analysis. Michigan Journal of Community Service Learning. 56-61 (2012).

13. Dorsey, B.: Linking Theories of Service-Learning and Undergraduate Geography Education. Journal of Geography. 100, 124-132 (2001).

14. Jordaan, M.: Community Project Module. Available online at http://www.up.ac.za/en/community-project-module/article/1949838/jcp-module [accessed 28 March 2016]. 
15. Mohan, J.: Thinking local: service-learning, education for citizenship and geography. Journal of Geography in Higher Education. 19, 129-142 (1995).

16. Duffy, J., Barry, C., Barrington, L., Heredia, M.: Service-Learning in Engineering Science Courses: Does It Work?. American Society for Engineering Education. (2009).

17. Giles, D.E., Eyler, J.S.: The impact of a college community service laboratory on students' personal, social, and cognitive outcomes. Journal of Adolescence. 17(4), 327-339 (1994).

18. Helzer, J.: elearning by Doing: A Geographic Approach to Service Learning and Building Community. The California Geography. 50, (2010).

19. Neuman, M.: Teaching collaborative and interdisciplinary service-based urban design and planning studios. Journal of Urban Design. 1-20 (2015).

20. Herkert, J.R.: Social, Ethical anti Policy Implications off Engineering. Wiley-IEEE Press (2000). 